\title{
Facilitators' adaptation practices of curriculum material resources for professional development courses
}

\author{
Nikola Leufer, Susanne Prediger ${ }^{*}$ D, Peter Mahns and Ulrich Kortenkamp
}

\begin{abstract}
Background: In STEM-innovation implementation processes, PD curriculum materials are designed to support facilitators in conducting professional development. However, little is known about the facilitators' practices in adapting PD materials. This study transfers frameworks from teachers' curriculum adaptation to facilitators and qualitatively investigates adaptation practices of 11 expert facilitators and their underlying individual perspectives in group discussion and interviews. In the study, a framework was developed for capturing facilitators' adaptation practices.

Results: The qualitative analysis shows that all so-called materialized adaptation actions (follow, omit, modify, sort, and create) are conducted on different grain sizes of PD material chunks and with various underlying perspectives. Additionally, thematic adaptation actions mainly refer to facilitators' ways of dealing with examples and theoretical constructs. Dealing with examples often involves shifts in forms of knowledge, e.g., when facilitators situate a theoretical construct in concrete classroom practices. The article contributes to theory generation on facilitators' adaptation practices, especially by introducing and illuminating the distinction between materialized and thematic adaptation actions.
\end{abstract}

Conclusion: The empirical insights of various underlying perspectives call for practical consequences for the design of PD curriculum material: To ensure that adaptation practices retain or improve quality, the structure of PD curriculum material must preserve the minimal adequate grain size (better the thematic block than the single slide) and the need for shifts in the forms of addressed knowledge.

Keywords: Professional development curriculum materials, Adaptation practices, Open educational resources, OER

\section{Introduction}

It is widely acknowledged that ensuring and improving high-quality teaching in STEM education requires teachers' professional development (PD) at scale. Consequently, as Coburn (2003) has emphasized, "the issue of 'scale' is a key challenge for school reform, yet it remains undertheorized in the literature" (p. 3). Within the last 15 years, scaling up has become a more systematic field of research in STEM education in which the institutional and systemic dimensions have been thoroughly investigated (Jacobs, Seago, \& Koellner, 2017; Roesken-Winter, Hoyles, \& Bloemeke, 2015). In many processes of scaling up, both the designers and facilitators of the courses conduct the

\footnotetext{
* Correspondence: prediger@math.uni-dortmund.de

Technische Universität Dortmund, Dortmund, Nordrhein-Westfalen, Germany
}

PD courses (Jacobs et al., 2017; Maaß \& Artigue, 2013). In spite of the central role of facilitators as key stakeholders in processes of scaling up (Jaworski \& Huang, 2014; Schifter \& Lester, 2002), their work has still rarely been investigated empirically, as two surveys show (Even \& Krainer, 2014; Jaworski \& Huang, 2014). Existing studies on facilitators mainly focus on facilitators' professional knowledge and facilitation practices (see Borko, Koellner, \& Jacobs, 2014; Even \& Krainer, 2014; Lesseig et al., 2017; Tekkumru-Kisa \& Stein, 2017).

In many scaling-up processes, the work of facilitators is substantially supported by PD curriculum resources, consisting of, for example, activity sheets, background literature, video clips, and input slides for PD sessions (Jacobs et al., 2017; Maaß \& Artigue, 2013). Similar to curriculum material for classrooms, this PD curriculum material is 
intended to guide the work, sometimes with the expectation of strict fidelity when implementation studies are conducted, but without expectation of strict fidelity outside of research contexts (Jacobs et al., 2017; LeMahieu, 2011). However, whereas teachers' creative use of classroom curriculum resources has been widely investigated and empirically explored (e.g., Brown, 2009; Davis, Beyer, Forbes, \& Stevens, 2011; Sherin \& Drake, 2009), little is as yet known about facilitators' adaptation practices of $\mathrm{PD}$ curriculum resources.

In our study, we explore facilitators' adaptation practices and disentangle the actions and underlying perspectives they use to adapt PD curriculum resources. Using this information, we aim to derive criteria for the design of such resources that support quality adaptations while overcoming the idea of fidelity (Butcher, 2015). Rather than requiring implementation fidelity, we consider adaptations necessary and investigate facilitators' perspectives behind their adaptations. For this purpose, we transfer to the facilitators' level theoretical frameworks developed for investigating teachers' adaptation practices for classroom curriculum resources and conduct a qualitative study about facilitators' adaptation practices and their backgrounds by analyzing group discussions and delayed interviews.

In line with this research goal, the first section outlines the theoretical framework and the second section the research context and the methodological framework. The third section presents the empirical results of the interview study in several steps of increasing depth.

\section{Theoretical background: conceptualizing adaptation practices and their bases}

\section{Existing research on facilitators and the research gap on} facilitators' adaptation practices

Two strategies can be distinguished to develop the work of facilitators in processes of implementation: The so-called personal strategy is defined as focusing on personal qualifications, i.e., on facilitator preparation programs, in order to strengthen their professional knowledge and practices. In addition, the socalled material strategy is defined as supporting facilitators by providing PD curriculum resources (Maaß \& Artigue, 2013). This section outlines that the current research on facilitators mainly informs the personal strategy, whereas a research base for the material strategy is still missing.

Since Schifter and Lester (2002) pointed to the huge gap in research about facilitators, several researchers have started to investigate facilitators' knowledge and practices and the strategies for supporting them. Most of the pioneer studies focused on facilitators' necessary knowledge and attitudes (summarized in Jaworski \& Huang, 2014; Even \& Krainer, 2014). Schifter and Lester
(2002) hypothesized that facilitators' expertise should include three key components: deep content knowledge, a clear view of the PD goals, and appreciation of the beliefs and understandings held by the PD participants. Borko et al. (2014) conceptualize "Mathematical Knowledge for Professional Development" (MKPD) as including (a) specialized content knowledge (e.g., deep understanding of the mathematics that stands at the core of the PD and how to make it accessible to all PD participants), (b) pedagogical content knowledge (e.g., how to engage teachers in productive analysis of instructional practices), and (c) learning community knowledge (e.g., how to establish group norms and foster active participation).

These studies contribute to a theoretical foundation for the personal strategy as they provide a language for specifying what facilitators need to be qualified for. These findings informed the development of instructional approaches for facilitator preparation courses (e.g., Borko, Jacobs, Koellner, \& Swackhamer, 2015; Kuzle \& Biehler, 2015; Maaß \& Doorman, 2013) and the investigation of facilitators' learning processes with respect to specific topics, such as the topic of facilitation moves (Lesseig et al., 2017).

In contrast, only few studies have been conducted that can inform the material strategy of providing PD curriculum materials. So far, facilitators' use of PD curriculum materials has mainly been investigated for controlling implementation fidelity, in that they have mainly been concerned with the degree to which a highly specified PD course is delivered as intended (Jacobs et al., 2017). Implementation fidelity is central to quantitative implementation studies (as requested by Dusenbury, Brannigan, Falco, \& Hansen, 2003), but this is a problematic criterion for authentic implementation processes as it denies the necessities of adapting to various learner groups and contexts (as criticized by LeMahieu, 2011; Stein, Remillard, \& Smith, 2007). Similar to studies on teachers' adaptation practices with classroom curriculum materials (see next section), facilitators' adaptation practices need to be investigated in their own right in order to disentangle the underlying perspectives and connections to facilitators' knowledge.

Understanding adaptation practices has become even more important since resources for STEM PD materials are offered as open educational resources (OER; Trouche, Gueudet, \& Pepin, 2018). The "open" in OER refers to open access, sharing sources, and especially, the flexibility and adaptability of materials by all sorts of different users (Wiley, 2014). Hence, the idea of OER explicitly rejects the idea of strict fidelity. This new quality of distributing materials has been promoted by UNESCO since 2002 in order to enhance scaling-up processes (Butcher, 2015) and 
is also highly relevant in our scaling-up contexts (as explained in the second section).

\section{General conceptual framework for disentangling teachers' and facilitators' practices by action and underlying category}

In our research, we build upon Bromme's (2001) widely cited conceptualization of professional expertise for operationalizing adaptation practices and the structure of the underlying perspectives. Bromme has conceptualized professional expertise as being shaped by (a) professional practices (defined as recurring patterns of combining actions for coping with situational demands) and (b) the underlying categories that guide the teachers' perceptions and actions in the practices. Thus, professional expertise is characterized as the competence to cope with the typical demands of professional life, such as noticing student thinking, mediating between materials and participants, and adapting materials to specific contexts and participants. To unpack teacher expertise, Bromme suggests focusing on specific situational demands and qualitatively analyzing the teachers' or facilitators' practices and the underlying categories. Practices are defined as patterns of actions that a professional typically applies. Categories are defined as those parts of the professional's (explicit or implicit) non-propositional knowledge that filter the perception and shape the individual's decisionmaking about actions. Usually, individual professionals have a much wider non-propositional conceptual knowledge than the parts they really refer to in their practices (other non-activated parts are called inert knowledge; see Renkl, Mandl, \& Gruber, 1996). Hence, in Bromme's (1992) approach, analyzing the situational demands with respect to the relevant practices and their underlying categories is a powerful "heuristic to search for the "natural' categories in expert knowledge" (p. 88).

In this paper, the situational demand in view is adapting PD materials to specific contexts and participants. We are using Bromme's (1992) construct of categories for the non-propositional knowledge that facilitators activate implicitly or explicitly when taking decisions on adaptations. The establishment of a concretized framework can start from lifting insightful findings from teachers' practices on the classroom level to facilitators' practices on the teacher PD level. To describe relevant reference points in teachers' and facilitators' practices (see Fig. 1), we rely on the Three-Tetrahedron Model established by Prediger, Roesken-Winter, and Leuders (2019) based on the didactical tetrahedron (Rezat \& Sträßer, 2012).

\section{A framework for adaptation practices based on existing research for curriculum materials}

Whereas little is known about facilitators' adaptation practices for PD curriculum materials, teachers' adaptation practices for classroom curriculum materials have been studied very carefully. Although working with different theoretical frameworks, we can find (a) justification for the general research focus and (b) candidates for typical adaptation actions, which are (c) transferred to the facilitators' practices on the teacher PD level, distinguished into two kinds of actions, and synthesized into a scheme. The literature on teachers' adaptations also provides (d) some points of reference for disentangling underlying categories for one kind, the so-called material adaptation actions, whereas to conceptualize underlying categories for thematic adaptation actions, (e) we refer to a preliminary study on facilitators. Aspects (a) to (e) are presented in the following to prepare the framework of this study.

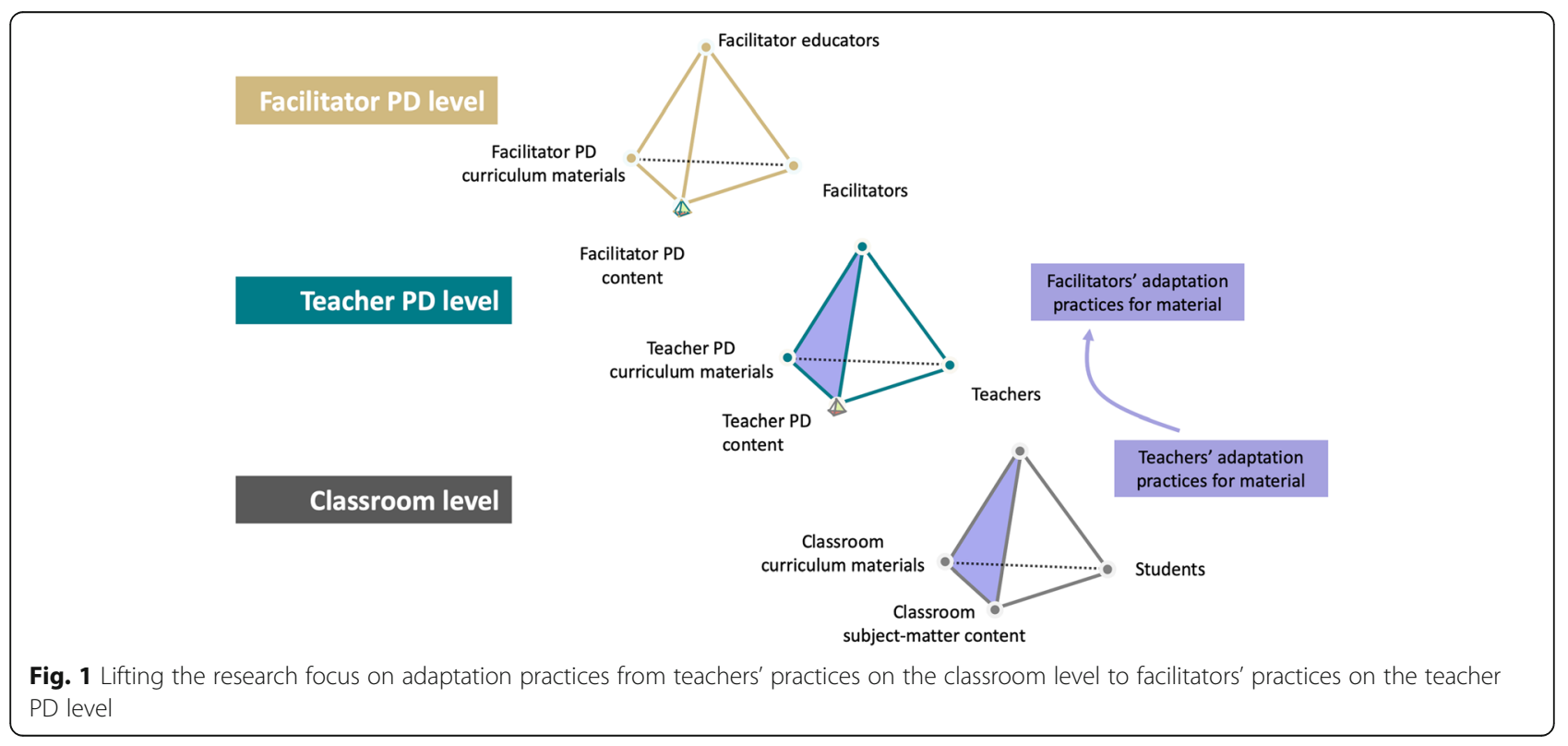


(a) Shift of research focus: accepting teachers' adaptation practices rather than surveying fidelity

In the early years of this research, teachers' adaptation practices were mainly investigated in terms of controlling the fidelity of implementation (for research overviews, see Stein et al., 2007; Sherin \& Drake, 2009). Early studies (e.g., Remillard \& Bryans, 2004) have described some teachers who followed the intended pathways very closely, especially when first using the material, while others adopt a more flexible use of materials, some going as far as detaching them from their original intentions.

Later, researchers suggested avoiding deficit-oriented perspectives and instead studying the teachers' practices in their own right (LeMahieu, 2011; Stein et al., 2007). In this new perspective, Brown (2009) conceptualizes teaching as a design activity that involves "a process of design in which teachers use curriculum materials in unique ways as they craft instructional episodes" (p. 18). Consequently, he defines the widely cited construct of teachers' "pedagogical design capacity" as teachers' capacity to perceive and mobilize existing resources in order to craft instructional episodes. He thereby suggests expecting adaptations rather than strict fidelity.

Brown (2009) lists several characteristics of curriculum materials that usually influence instruction, emphasizing the dynamic nature of the practices as curriculum materials rely heavily on interpretation: "Curriculum materials require craft in their use; they are inert objects that come alive only through interpretation and use by a practitioner" (p. 22).

\section{(b) Points of reference for disentangling teachers' adaptation practices into adaptation actions}

Brown's (2009) list of characteristics supported a shift of research focus, not if the teachers adapt curriculum materials, but how they do it and by making use of which underlying personal resources (knowledge, categories, etc.). The subsequent research used interviews and narratives with teachers' self-reports about their intended curriculum (e.g., Davis et al., 2011) and classroom observations to capture the enacted curriculum and the teachers' underlying reasoning (e.g., Sherin \& Drake, 2009).

Brown (2009) identifies three typical practices by which teachers appropriate new curriculum materials: Offloading occurs when teachers follow curriculum materials closely, giving agency to the materials for guiding instruction. On the other end of the spectrum is improvising, when teachers shape instruction spontaneously and/or without specific guidance from their materials, relying mainly on their own design initiatives and thus shifting agency to themselves. In between, adapting occurs when teachers modify their materials to support instructional goals, thus sharing agency between themselves and the materials. In his research, Brown seeks to explain these practices within and across teachers and examines how teacher knowledge, goals, and values come into play.

As Sherin and Drake (2009) point out, engagement with curriculum material can be examined before, during, or after instruction. During each of the time periods, they see a teacher's curriculum strategy as consisting of three interpretative practices: reading, evaluating, and adapting (Sherin \& Drake, 2009, p. 472). To disentangle the practices of adapting, Sherin and Drake (2009) describe a continuum of adaptation actions between omit, replace, and create. Most researchers found evidence for adaptation actions in the middle of the spectrum, naming them differently, for example, extending, complementing, or modifying (e.g., Davis et al., 2011; Remillard, 2005; Remillard \& Bryans, 2004). Modifications do not only concern external actions on the material itself but also the themes within the material. For example, teachers change the priority of forms of knowledge by flattening conceptual activities using procedural routines. Even without materially modifying the material, these adaption actions shape the core of the enacted curriculum (Davis et al., 2011).

\section{(c) The FOMSC scheme as a framework for facilitators' adaptation actions}

To establish a framework for facilitators' adaptation practices, we lift the approach (reported on the classroom level for teachers) of disentangling adaptation practices into well-defined adaptation actions to the facilitators' practices. Taking into account the different nature of adaptations found for teachers, we introduce a new distinction into materialized and thematic adaptation actions. Thematic adaptation actions are defined as those referring to the themes within the materials, even if the material is not materially modified. Materialized adaptation actions are defined as those that refer to concrete pieces of materials with actions visible in the material.

We synthesize the actions identified for teachers into the FOMSC scheme (Fig. 2), which distinguishes five materialized adaptation actions:

- FOLLOW, e.g., following one thematic block of the material as originally designed

- OMIT, e.g., omitting a certain activity or thematic block

- MODIFY, e.g., modifying a module, which always implies other adaptation actions on the material elements of which the module consists (one module can consist of several thematic blocks)

- SORT, e.g., modifying a module by resorting its thematic blocks into a new order

- CREATE, i.e., developing a new activity within a thematic block 


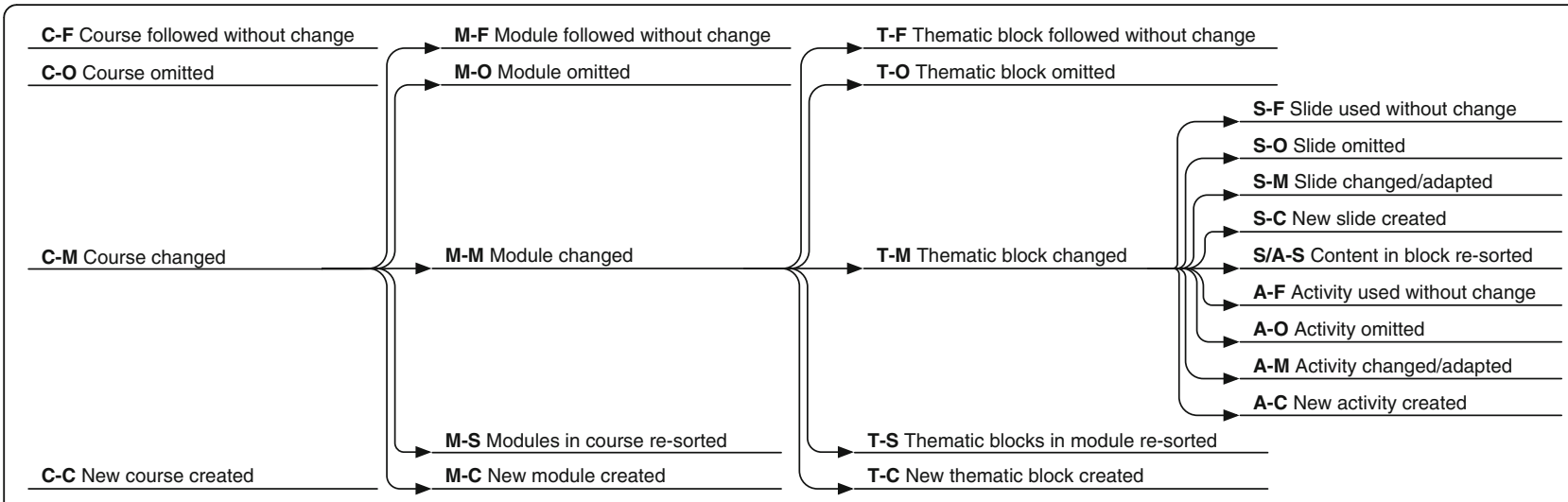

Fig. 2 FOMSC scheme as a framework for materialized adaptation actions in different grain sizes of material

As the research on teachers' adaptation has shown, materialized adaptation actions encompass different grain sizes (courses, modules, thematic blocks, activities, or slides, similar to Davis et al., 2011): Teachers or facilitators can CREATE or OMIT single activities, slides, thematic blocks, or even complete modules.

In order to account for these different grain sizes with all theoretically possible actions, we adopt an approach for typical basic operations in persistent data sets (Martin, 1983) and create the FOMSC scheme with action at five grain sizes: course $(C)$, module $(M)$, thematic block $(T)$, slide $(S)$, or activity (A). Figure 2 visualizes the hierarchical structure: The CHANGE of a module consists of OMIT, CHANGE, or CREATE in some thematic blocks and so forth.

Thematic adaptation actions can involve giving the curriculum material another meaning without materially changing it. For example, the function of an illustrative example changes when its meaning gets detached from the theoretical construct it was originally meant to explain. So far, different thematic adaptation actions have not been classified, although they may also be important for teachers. Thus, identifying different thematic adaptation actions is an empirical task calling for an inductive research approach.

\section{(d) Points of reference for disentangling underlying categories for materialized adaptation actions}

Whereas researchers have found some convergence in the extrapolated teachers' materialized adaptation practices as combinations of different adaptation actions, the investigation of the underlying perspectives has drawn upon different conceptualizations (see Stein et al., 2007, for an overview).

To unpack the bases for teachers' curricular decisions, Davis et al. (2011) refer to explicitly consulted knowledge (e.g., pedagogical content knowledge about students), experiences (e.g., previous teaching experiences and PD experiences), and resources (e.g., lesson ideas from the curriculum material in view, student texts, and colleagues). The knowledge can refer to the learners, the content, and the circumstances, among others.
For our framework for facilitators' adaptation practices based on Bromme (1992), we focus on the nonpropositional part of knowledge, the categories that shape the noticing and thinking about all three areas, and the content and the circumstances and their relations. As the latter analysis will show, categories contain, for example, "teachers' starting points in the learning process" or "the danger of teachers' theoretical overload." We assume the concrete facilitators' categories to be different from the teachers' categories, so, again, an inductive research approach is required to identify them.

\section{(e) Points of reference for underlying categories for thematic adaptation actions}

Since facilitators' important roles in adapting PD curriculum materials have already been problematized briefly by Stein, Smith, and Silver (1999), each implementation study seeking quantitative evidence of effectiveness while scaling up must control the facilitators' adaptations in a fidelity perspective (more recently in Jacobs et al., 2017).

However, only one study was found that investigated both facilitators' adaptation practices and facilitators' underlying perspectives, from which we can draw possibly relevant categories: In a preliminary case study with 11 facilitators, Zwetzschler, Rösike, Prediger, and Barzel (2016) provided insights into the adaptation practices of two facilitators. While both facilitators report that they do not technically modify the given materials (no reported materialized adaptation actions), they also report that they mainly prioritize the classroom task examples while neglecting the more general ideas and theoretical constructs behind the examples. These empirical insights into thematic shifts have motivated the introduction of the construct thematic adaptation action.

When analyzing the categories that led the facilitators' thematic adaptation actions, the preliminary study revealed the facilitators' specific understanding of participant orientation as a guiding category: The facilitators' interpretation was that their participants needed 
concrete guidance for action in the classroom using implementable tasks. This individual version of participant orientation is directly connected to the different forms of knowledge they aim at: The facilitators seem to ground their adaptations on their understanding of the specific character of the knowledge to be acquired and their perceptions of the teachers' learning needs and learning intentions. To capture the facilitators' reasoning about the knowledge the participants should acquire, the relation of concrete examples and background constructs in particular turned out to be crucial. Thus, the researchers draw upon a distinction of forms of knowledge introduced by Cochran-Smith and Lytle (1999) and partly adapted by Zwetzschler et al. (2016):

- Knowledge-in-practice is defined as teachers' practical know-how for classroom practices that is often acquired by experience or transferred by concrete guidelines ("recipes") for actions and classroom examples to be applied, for instance, by concrete tasks or activity structures.

- Knowledge-for-practice is defined as knowledge for classroom practices that is often developed outside classrooms, for instance, in research units of universities. It comprises theoretical constructs and more general backgrounds behind the know-how. Cochran-Smith and Lytle (1999) emphasize that expert teachers can translate knowledge-for-practice into knowledge of more practical value. Our empirical study will show that facilitators often see the need to promote these translation practices themselves.

- Knowledge-of-practice is defined as the conceptual and interpretative framework of teachers by which they embed and systematize experiences and reflect and evaluate them. It is usually developed by experimenting and reflecting through connecting to some theoretical constructs.

Even if Cochran-Smith and Lytle (1999) introduced these distinctions in a macro perspective, for complete styles of professional development programs (with a focus on advertising action research for promoting knowledge-of-practice), the distinction has proven to be of value in a micro perspective, describing much more subtle shifts of forms of knowledge aimed at within the same PD course (e.g., Zwetzschler et al., 2016). They are hence interesting sensitizing constructs for disentangling the facilitators' perspectives underlying the thematic adaptation actions.

Conceptual framework for facilitators' adaptation actions and underlying categories

To sum up, for investigating facilitators' adaptation practices, lifting research findings from the teachers' practices to facilitators' practices seems highly valuable, as it allows the conceptualization of adaptations not as a threat to implementation fidelity but as a desirable and necessary professional practice by which facilitators' pedagogical design capacity can unfold.

The conceptual framework within this study builds upon Bromme's (2001) conceptualization of professional expertise by investigating facilitators' practices in the situational demand of adapting PD materials. In line with the current research on teachers' adaptation practices, the conceptual framework describes the facilitators' practices in terms of concrete actions and the underlying categories that guide the teachers' perceptions and actions.

Materialized adaptation actions can be described using the FOSMC scheme (Fig. 2), but the underlying categories must be identified empirically. Thematic adaptation actions seem to concern the ways of treating theoretical constructs and examples, but also must be identified empirically in more detail. The underlying categories seem to concern individual ideas of participant orientations and the forms of knowledge (knowledge-in-practice, knowledge-for-practice, and knowledge-of-practice, following Zwetzschler et al., 2016) that the facilitators intend to construct. This conceptual framework provides the sensitizing constructs for the empirical study.

\section{Research questions}

Based on the existing state of research, we pursue the following research questions:

How do facilitators adapt PD curriculum materials, and which underlying individual perspectives guide their decisions?

Within the established framework, this research question can be rephrased in a refined way:

RQ1: Which materialized adaptation actions do facilitators conduct with the PD materials, and by which underlying categories are these actions guided?

RQ2: Which thematic adaptation actions do facilitators conduct with the PD materials, and by which underlying categories are these actions guided?

The descriptive and explanative empirical findings will be used to formulate prescriptive consequences, namely empirically grounded criteria for designing open educational resources.

\section{Methodological framework and research context Research context and methods of data gathering Research context and structure of the PD material}

The empirical study was situated in the research context of the Deutsches Zentrum für Lehrerbildung Mathematik (DZLM; the German Center for Mathematics Teacher Education), which combines the personal and the material strategy for reaching about 700-1000 mathematics 
facilitators in Germany (Prediger et al., 2019; RoeskenWinter et al., 2015). By offering PD materials as OER in the material strategy, the DZLM also intends to reach not only new facilitators. But also those with several years of job experience. Based on the present state of research, the DZLM does not treat facilitators as "program providers" expected to deliver a PD program with fidelity (Dusenbury et al., 2003) but as reflective practitioners who adapt materials based on own perspectives and their pedagogical design capacity (Brown, 2009).

Within the research context of the DZLM, PD curriculum materials for language-responsive mathematics teaching were developed and investigated first with respect to teachers' learning processes (Prediger, 2019) and now also considering facilitators' adaptation practices. In addition to theory generation on typical adaptation practices, the aim of this research is also to inform the improvement of the material according to criteria for OER. Extrapolating typical adaptation actions and understanding the individual perspectives that guide them are crucial for our overall goal to provide OER that support quality adaptations while overcoming the idea of fidelity.

The specific PD material in view (Eisen et al., 2017) was developed in order to include it in an existing PD program for novice mathematics teachers who have recently graduated from university. The general practical PD program lasts 18 months with about 30 sessions on mathematics education and is accompanied by an intensive program where PD facilitators conduct weekly mathematics education PD course sessions and regularly visit the novice teachers' mathematics classrooms.

The design of the complementary PD material followed a request by the government to also prepare teachers for language-responsive mathematics teaching. The design team consisted of researchers in mathematics and language education and expert facilitators with the same status as those investigated (not included in the sample).

The study of adaptation practices was situated in the pilot phase of the development process. After the pilot phase and the study of facilitators' adaptations, the design team revised the PD curriculum materials and handed them over to all facilitators in the PD institutions for novice teachers in the state Northrhine-Westfalia and all over Germany in digital formats as OER.

The PD material on language encompasses 10 modules consisting of activities and video clips or students' processes or classroom talk situations, background literature, a facilitators' manual, and slides with comments to support the course work. Each module carries an additional thematic structure by which slides and activities are grouped into coherent blocks. Figure 3 shows an overview of the language PD material and proposes

\begin{tabular}{|c|c|c|c|}
\hline \multicolumn{2}{|c|}{$\begin{array}{l}\text { Ten modules on language-responsive } \\
\text { mathematics teaching }\end{array}$} & \multirow{2}{*}{$\begin{array}{l}\text { Topic of established mathematics education } \\
\text { session in which the module can be integrated } \\
\text { (single session) }\end{array}$} & \multirow{6}{*}{$\begin{array}{l}\text { Components of a module: } \\
\text { Several thematic blocks con- } \\
\text { sisting of } \\
\text { - slides with inputs } \\
\text { and reflections } \\
\text { - video clips of classrooms } \\
\text { - activity sheets } \\
\text { Facilitator's manual } \\
\text { Background literature }\end{array}$} \\
\hline 6 & $\begin{array}{l}\text { Basic module (background on } \\
\text { academic language demands in } \\
\text { math learning) }\end{array}$ & & \\
\hline & $\begin{array}{l}\text { Language learning goals } \\
\text { supporting mathematical goals }\end{array}$ & $\begin{array}{l}\text { Specifying mathematical learning goals } \\
\text { OR creating lesson plans }\end{array}$ & \\
\hline & $\begin{array}{l}\text { Sequencing mathematical and } \\
\text { language learning trajectories }\end{array}$ & Planning a teaching unit & \\
\hline & $\begin{array}{l}\text { Relating registers and } \\
\text { representations }\end{array}$ & $\begin{array}{l}\text { Promoting conceptual understanding } \\
\text { OR e.g. understanding fractions }\end{array}$ & \\
\hline 28 & Supporting language & $\begin{array}{l}\text { e.g. geometry education OR probability } \\
\text { education }\end{array}$ & \\
\hline & $\begin{array}{l}\text { Practising phrases and } \\
\text { discourse practices }\end{array}$ & Exercises for intelligent training & \\
\hline & $\begin{array}{l}\text { Activity structures for } \\
\text { enhancing communication }\end{array}$ & $\begin{array}{l}\text { Cognitive activation OR } \\
\text { Activity structures for engaging all students }\end{array}$ & \\
\hline हि? & $\begin{array}{l}\text { Moves for demanding and } \\
\text { supporting discourse practices }\end{array}$ & Moves for mathematically rich classroom talk & \\
\hline$+1 x^{3}$ & $\begin{array}{l}\text { Differentiating tasks in their } \\
\text { language demands }\end{array}$ & Differentiation with tasks & \\
\hline 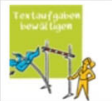 & $\begin{array}{l}\text { Fostering students' strategies } \\
\text { for dealing with word problems }\end{array}$ & Modelling & \\
\hline
\end{tabular}


possible sessions into which it can be included. The PD material supplies a surplus of ideas and activities so that all facilitators have to do are select a small part of the material that fits their time and theme frames and adapt it to their current novice teachers' experiences and learning needs.

\section{Sampling of expert facilitators for group discussions}

The preliminary study (Zwetzschler et al., 2016) requires further extensions with respect to the sampling of facilitators: Whereas the preliminary study revealed insights into problematic adaptation practices, the sampling of the current study explicitly focused on more experienced facilitators and more mature PD material in order to reduce the research gap in facilitators' adaptation practices and to avoid a deficitoriented view of facilitators.

Therefore, the sample of PD facilitators chosen was an expert group, consisting of 11 expert facilitators who worked at least half-time for the PD institution for novice teachers and half-time as teachers or in PDs for more experienced teachers; they each had at least 10 years of mathematics teaching experience and at least 5 years of facilitating experience. The structure of the novice teacher education program in which they worked guaranteed intense participant contact because of their regular classroom visits. The 11 expert facilitators were chosen by the district authorities (among volunteers for the pilot phase). The selection criterion was their general mathematics education expertise, and eight out of the 11 were not yet familiar with language-responsive teaching.

During the 12 months of the pilot phase, the facilitators and the design team met on 5 days to work on the topic of language-responsive mathematics teaching and to introduce the material. After day 2, the facilitators started experimenting with the material in their PD courses, and on days $3-5$, they discussed their adaptations and experiences. The researchers' minutes of approximately $6 \mathrm{~h}$ of group discussions on adaptations and experiences are the first part of our data corpus.

To sum up, this best practice sample of expert facilitators had conditions and a general working situation that was advantageous (half-time accompanying novice teachers allows intense work on new topics) in the intensity of introduction to the new PD materials during the pilot phase.

\section{Sampling for interviews and interview protocol}

Seven to 10 months after the pilot phase, semistructured interviews were conducted with six facilitators (the others were not available for interviews).
Two, here called Ms. Rice and Ms. Sour, had participated in qualifications on the topic of language responsiveness prior to the pilot phase, while for four, here called Mr. Soc, Ms. Blake, Ms. Farm, and Mr. Narr, the pilot phase was the first encounter with the new topic.

The long-distance interviews were conducted in Adobe Connect meetings by researchers who did not participate in the design team. They lasted approximately $60 \mathrm{~min}$ each and followed a semi-structured interview protocol.

The interviews were based on the individually adapted materials that were analyzed beforehand by the interviewers. The questions of the semi-structured interview protocol were collected in accordance with the theoretical framework and the preliminary insights from the group discussions. They covered questions and discussion points about the relevance of the topic of languageresponsive mathematics teaching for themselves and their novice teachers, their use and adaptations of the curriculum materials, the reasons for adaptations and the evaluation of observed effects for the novice teachers, and their future plans for further adaptations. The interviewers also situatively provoked reflections and evaluations on adaptation practices in order to capture the facilitators' underlying ideas. The second part of the data corpus thus comprises the transcribed videos from the interviews and the facilitators' adapted PD materials.

\section{Methods of data analysis}

The facilitators' adapted materials and the transcripts of the interviews were qualitatively analyzed in MaxQDA using the following steps:

\section{Step 1: Deductive coding of the materialized adaptation actions}

For the materialized adaptation actions, a deductive coding procedure was conducted using the FOMSC scheme (see Fig. 2). The facilitators' materialized adaptation actions were assigned to the codes FOLLOW (F), OMIT (O), MODIFY (M), SORT (S), and CREATE (C). In addition, the grain sizes to which they referred were assigned as follows: Course (C), Module (M), Thematic Block (T), Slide (S), and Activity (A). The corresponding codes in the FOMSC scheme, for instance, M-F, T-O, and $\mathrm{S}-\mathrm{C}$, inform about the granularity of the adaptations by the facilitators. Note that $\mathrm{C}-\mathrm{O}$ (omitting the whole course) and C-F (following the whole course without change) are unlikely to happen, and C-S (re-sorting courses) is impossible as we only considered a single course. T-S (re-sorting thematic blocks) is a sub-code of $\mathrm{M}-\mathrm{M}$ (modifying modules). 


\section{Step 2: Inductive development of codes for thematic adaptation actions and categories}

For the thematic adaptation actions and the underlying categories for materialized adaptation actions, the coding schemes were developed by inductive analytic procedures adapted from Mayring (2015). Starting with summarizing the content analysis, codes were developed and systematized with the following sensitizing constructs:

- For the thematic adaptation actions, the specific focus was set on capturing how the facilitators dealt with theoretical constructs and classroom examples, as these were relevant in the preliminary study.

- For the individual categories guiding the actions, the relation of the facilitator to the PD curriculum material is orientated by considerations about the two remaining vertices in the PD tetrahedron, the teachers as learners and the PD content itself, and the circumstances (see Fig. 4).

Once the material was inductively coded in the three areas, the codes were consolidated by systematically contrasting and comparing them within and across the cases. In addition, codes in the coding scheme were adapted to the language of the database operations that refine the existing codes. The resulting scheme of adaptation actions is presented as a first descriptive result that could also be quantified by determining frequencies. The explanative results comprise the resulting schemes for the underlying individual categories. About 150 codes were assigned for each interview transcript.

\section{Step 3: Deeper analysis with respect to transformation of forms of knowledge}

A deeper, more local analysis was conducted for the thematic adaptation actions and the underlying individual

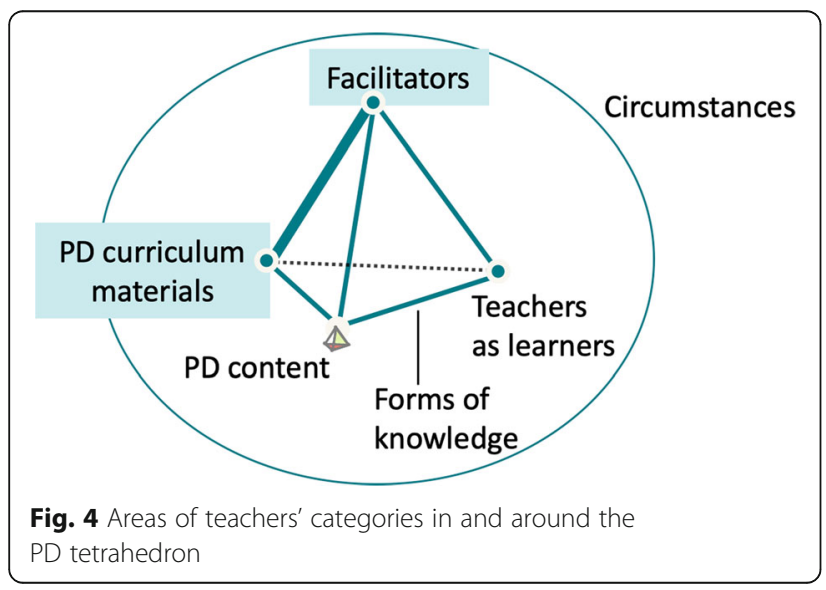

categories by relating them to the facilitators' perspectives on the forms of knowledge their participants should acquire (hence situated on the edge between PD content and teachers as learners, although addressing aspects of the nested classroom tetrahedron). Following the analytic procedures suggested by Zwetzschler et al. (2016), the orientations of facilitators' adaptation actions can be characterized as addressing different transformations of knowledge-inpractice, knowledge-for-practice, and knowledge-ofpractice (see above). This analysis provides explanative insights into more subtle practices and reasoning and informed revisions of the material.

\section{Step 4: Triangulation with the observations from the group discussions in the pilot phase}

As the interviews with six focus facilitators took place several months after the introduction of the material and can only provide a very specific insight into facilitators' practices, the findings from Steps 1 to 3 were triangulated by analyzing (in a deductive procedure with existing codes) the minutes of the group discussions in the pilot phase, which revealed similar patterns.

\section{Results on facilitators' adaptation practices}

The results comprise descriptive and explanative findings on (a) materialized adaptation actions and (b) their underlying categories, (c) thematic adaptation actions, and (d) their underlying categories.

(a) Describing facilitators' materialized adaptation actions To identify the adaptation actions the facilitators made, the analysis of the adapted material was equally important as that of the facilitator's self-reports in the group discussions and interviews. As expected, all facilitators followed some parts of the PD material and omitted other parts; this selection was unavoidable due to the surplus of the provided material.

None of the 11 facilitators omitted the whole course, and only a single module was followed by each facilitator without change. Integrating a thematic block or activity into an existing module addressing other topics of mathematics education was explicitly invited by the construction of the modules and took place in various ways. The group discussions revealed that many facilitators reorganized the modules or thematic blocks by re-sorting them. Astonishingly enough, this materialized adaptation action did not yet occur in the literature on teachers. A specific version of the action change is "click through and select spontaneously," by which the facilitator can react adaptively to the course of the discussion or improvise with the material for other reasons (Brown, 2009): For instance, Ms. Rice reported, "The module 
[had many repetitions to the basic module], so I clicked through and ... selected certain slides saying something knowledgeable ...." (Ms. Rice, Interview Turn 14). As these kinds of adaptations are not visible in the materials and not mentioned in group discussion, the interviews became the main data source.

Figure 5 shows the comparison of the six interviews with respect to the frequency of mentioned materialized adaptation actions for different grain sizes of the materials: complete modules and single activities or thematic blocks within a module. The size of the printed points indicates how often each code was mentioned in the interview.

Whereas some facilitators (Ms. Blake and Mr. Narr) concentrated their reports on materialized adaptation actions mainly on the grain size of modules by creating and omitting thematic blocks, others (Ms. Rice, Ms. Farm, and Mr. Soc) report having modified the blocks themselves. Ms. Blake made selections of modules and thematic blocks, but reported many instances of having used activities without change. In contrast, Ms. Rice reported many changes of single slides and activities and re-sorting the order of the slides and activities. Her utterances provide indications of substantial thematic changes with respect to using examples and using theoretical constructs. These differences must be taken into account by analyzing the thematic adaptation actions (see below). It is interesting that so far, most facilitators rarely changed single slides.

\section{(b) Explaining the materialized adaptation actions by} underlying individual categories

The diversity of adaptation actions and different priorities resonates with the diversity of individual categories that could be identified as underlying these practices. Table 1 shows the codes that were developed for the underlying categories that occurred most often.

Ms. Rice, the expert facilitator who reported on many modifications of single slides and activities (see Fig. 5), sometimes mentioned the circumstances, for instance, while drawing upon the necessary fit to the existing PD syllabus. However, she more often related her reasoning to the needs of the participants and to careful reflections of the PD content languageresponsiveness.

For example, she mentions how she evaluates the novice teachers' learning processes:

The novice teachers have to think about what the pupils should do and how they have to communicate this.... In any case, this has truly been worthwhile, because no matter at what point and no matter how smoothly this worked out, they were always forced to reflect on it in advance and to anticipate. (Ms. Rice, Interview Turn 12)

She optimizes her adaptation of an activity with respect to the goal of forcing the novice teachers' towards thinking about students' activities. It seems to be characteristic for

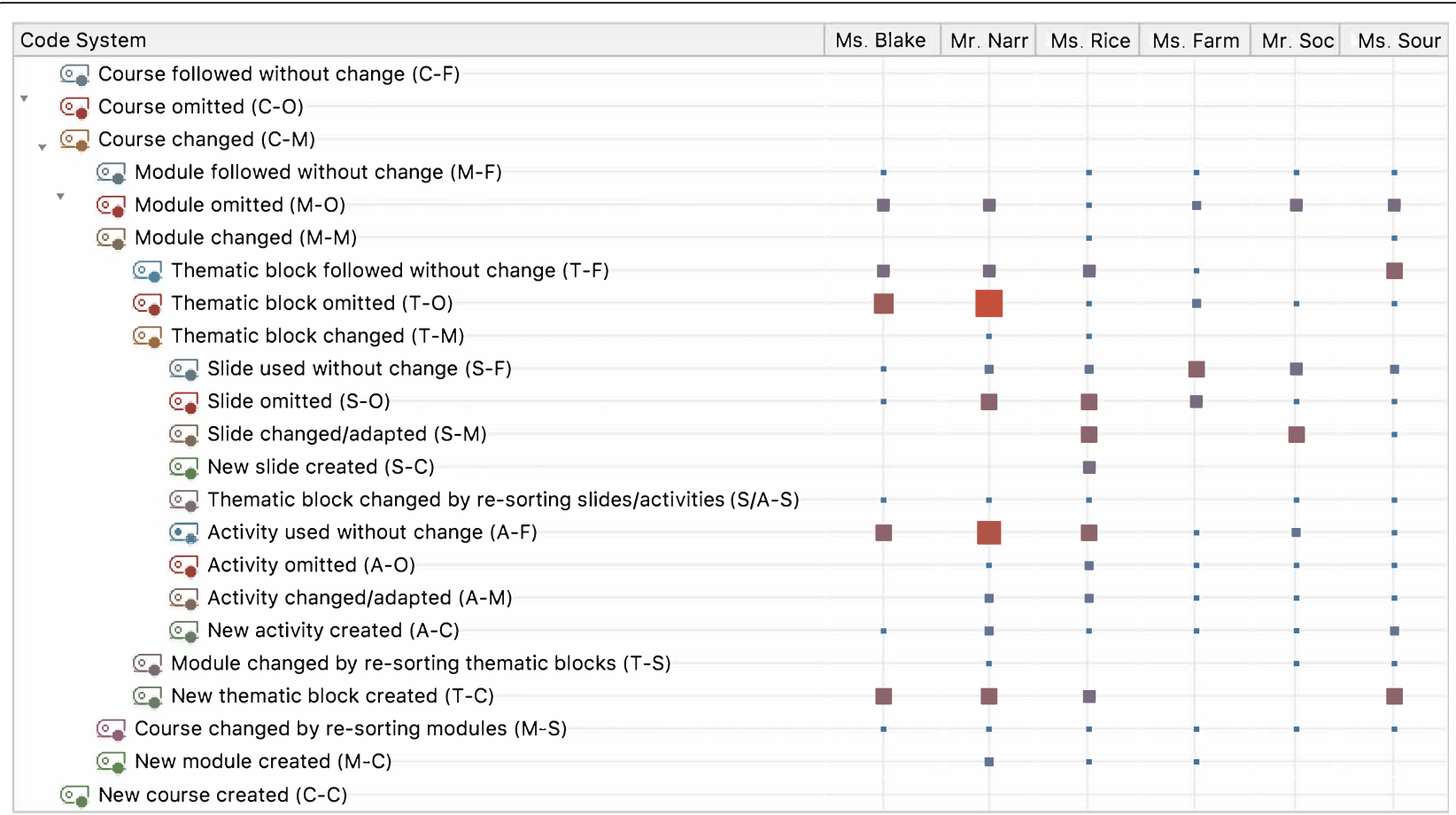

Fig. 5 Code matrix highlighting the frequency of materialized adaptation actions in six interview transcripts 
Table 1 Individual categories underlying the facilitators' materialized adaptation actions

\begin{tabular}{|c|c|}
\hline Individual category & Example from the transcripts (translated from German) \\
\hline \multicolumn{2}{|l|}{ Categories with respect to teachers as learners } \\
\hline $\begin{array}{l}\text { Accounting for novice teachers' learning starting } \\
\text { points }\end{array}$ & $\begin{array}{l}\text { "One participant brought in ... [ideas from preliminary courses] and then we talked about } \\
\text { it.... There, I think, it has proven useful, that they had heard that before." (Ms. Sour, } \\
\text { Interview Turn 98) }\end{array}$ \\
\hline $\begin{array}{l}\text { Accounting for perceived learning needs, especially } \\
\text { support for concrete teaching demands }\end{array}$ & $\begin{array}{l}\text { "And, first of all, they are expected to teach autonomously. And then they need to plan } \\
\text { teaching units and lessons. Previously I have started my seminars with planning a [single] } \\
\text { lesson but... they need the context in which it is embedded and not to start from the } \\
\text { single lesson goal." (Ms. Rice, Interview Turn 50) }\end{array}$ \\
\hline $\begin{array}{l}\text { Accounting for danger of novice teachers' theoretical } \\
\text { overload }\end{array}$ & $\begin{array}{l}\text { "I have chosen to take a different path, as I once had started with the basic module which } \\
\text { totally overstrained my folks." (Mr. Soc, Interview Turn 31) }\end{array}$ \\
\hline $\begin{array}{l}\text { Accounting for the school context of the individual } \\
\text { novice teacher }\end{array}$ & $\begin{array}{l}\text { "Do you have to show the relevance [of language] for the context?" ... "There are } \\
\text { comprehensive schools and grammar schools as well, depending on their social } \\
\text { catchment area, where it is specifically important." (Ms. Sour, Interview Turn 122) }\end{array}$ \\
\hline Evaluating novice teachers' learning processes & $\begin{array}{l}\text { "The novice teachers have to think about what the pupils should do and how they have } \\
\text { to communicate this.... In any case this has truly been worthwhile, because no matter at } \\
\text { what point and no matter how smoothly this worked out, they were always forced to } \\
\text { reflect on it in advance and to anticipate." (Ms. Rice, Interview Turn 12) }\end{array}$ \\
\hline
\end{tabular}

\section{Categories with respect to perceived characteristics of the PD content language-responsiveness}

Thematic focus/theoretical construct is (perceived as) difficult

Inner structure of the PD content requires other sequencing

Thematic focus is already known

Fit to the mathematical topic in view

Relevance of the thematic focus

\section{Categories with respect to circumstances}

Fit to overarching PD program

Fit to sequence structure of the PD material

Restrictions by time frame until autonomous teaching

Restrictions by organizational time frame
"Well, no idea. I found that rather difficult for me.... But sometimes I really doubted whether you can expect this [theoretical construct] of them." (Ms. Rice, Interview Turn 8)

"They need to understand the epistemic function of language before they can plan a teaching unit." (Ms. Farm, Group Discussion 3)

"I found indeed that the modules for the learning target and activating the communication were well-unnecessary. Actually, there was nothing new to me in the sense of an insight or a basic idea that I could not have integrated before." (Mr. Soc, Interview Turn 80)

"I embedded the example with fractions when we were talking about fractions." (Ms. Blake, Group Discussion 2)

"If I cannot express something . . . I cannot understand it. In some way I must be able to verbalize things that I want to understand. Establishing connections and explaining as well, there's students' problem." (Ms. Sour, Interview Turn 14)

"Why have you chosen the modules 'targets' and "?" . . I have worked through the topics of the project materials, but in the end these are the normal topics you discuss in the seminars." (Ms. Rice, Interview Turn 20)

"After all, the PD syllabus outlines quite a bit, what they need to have covered in the first quarter, like, from now on until summer break, and that's what I consider." (Ms. Sour, Interview Turn 131)

"And also regarding the time aspect, because we can only dispose of [the time range] from May until summer break to get them to the point where they are able to teach autonomously." (Ms. Sour, Interview Turn 51)

"I've made the decision to take another way. ... . simply without theoretical lead-in, as part of a group observation, which already is planned within the scope of a day of study here. . and then only as a second step..." (Mr. Soc, Interview Turn 31) this group of expert facilitators to intensively observe what the participants need. At the same time, she has the capacity to reflect deeply on the PD content and decide which theoretical construct is difficult for them to understand:

Well, no idea. I found that rather difficult for me.... But sometimes I really doubted, if you can expect this [theoretical construct] of them. (Ms. Rice, Interview Turn 8)
Combined with a strong orientation towards the learning needs of their novice teachers, five out of the six facilitators consequently related the PD thematic focus to the teachers' possible next steps of development. In this way, the facilitators showed a high degree of "pedagogical design capacity" (in the sense of Brown, 2009), as they make use of their strong background for participant orientation and work on achieving high adaptivity. 
As expected, these findings on underlying categories for materialized adaptation actions resonate strongly with findings on teachers' practices (Brown, 2009; Sherin \& Drake, 2009). In contrast, new insights occur for the thematic adaptations, as described in the next section.

(c) Describing facilitators' thematic adaptation actions Whereas the facilitators' materialized adaptation actions were captured using the deductively constructed FOSMC scheme, thematic adaptation actions had to be identified inductively. Table 2 shows all developed codes for thematic adaptation actions involving examples and theoretical constructs that are addressed several times by the expert facilitators in the interviews, visible in their adapted materials, or discussed in the group discussions.

The follow, omit, and create actions all occur again, but there is also a huge variety of further adaptation actions. We discuss them in terms of their direct relations to the underlying categories in the next section.

\section{(d) Explaining thematic adaptations using underlying categories: priorities and transformations of forms of knowledge}

The inductive analysis of our interview and group discussion data revealed that the facilitators' thematic adaptation actions were usually guided by their individual negotiation of the structure of the PD content and their understanding of their participants' learning needs, which we will substantiate with interview excerpts in the following. As an interpretative scheme to grasp and classify these processes of negotiating, we refer to the different forms of knowledge introduced in the theoretical section: Aiming at educating their participants to be successful practitioners, the distinction of knowledge and classroom practice becomes ambiguous and serves as an informative lens through which to look at the facilitators' interview data.

\section{Knowledge-for-practice valued for facilitators' background}

All facilitators valued the research-based knowledge-forpractice provided by theoretical constructs and principles in the modules for enriching their own theoretical background. They conceived the work with the PD materials and the preparation meetings as interesting learning opportunities for themselves, appreciating, for example, empirical insights into the epistemic function of language in the students' mathematical learning processes. However, they saw the need to substantially reduce or transform the theoretical constructs and empirical findings for their novice teachers.

The basic module of a course [serves] as a background for facilitators, but the novice teachers do not need to work through it. (Ms. Sour, Interview Turn 51)

Do you think it is good that you have a broad selection and you can select the topics you want? ... I do think it is good as it is a broad selection, because it offers me a broad basis for actions. (Ms. Sour, Interview Turn 112)

My essential task is to select. Especially the slides I want to use from the presentation.... But for my own knowing-how and, like I said, to be able to spontaneously add something if necessary, I think it is good to have a broad selection. (Mr. Soc, Interview Turn 29)

Table 2 Expert facilitators' thematic adaptation actions: descriptive results of the category formation process

\begin{tabular}{|c|c|}
\hline Code for thematic adaptation action & Explanation of the code \\
\hline \multicolumn{2}{|l|}{ Dealing with classroom examples } \\
\hline FOLLOW example with its theoretical embedding & An example and its embedded theoretical constructs are used without bigger modifications. \\
\hline DETACH example from its theoretical embedding & $\begin{array}{l}\text { An example is used, but without the theoretical constructs it was originally intended to } \\
\text { illustrate. }\end{array}$ \\
\hline SELECT/ADJUST to actual classroom contexts & $\begin{array}{l}\text { Some examples are omitted that do not fit to the classroom challenges; others chosen in } \\
\text { order to assure a good fit with the current grade levels or mathematical topics the novice } \\
\text { teachers are working with. }\end{array}$ \\
\hline $\begin{array}{l}\text { CREATE own example for integrating theoretical } \\
\text { constructs }\end{array}$ & $\begin{array}{l}\text { A completely new teaching unit is developed by a facilitator in order to integrate all relevant } \\
\text { constructs. }\end{array}$ \\
\hline Let examples be ADAPTED/EXTENDED & $\begin{array}{l}\text { The novice teachers are guided to develop or extend examples that fit to their actual } \\
\text { classroom contexts and deepen the theoretical approach. }\end{array}$ \\
\hline \multicolumn{2}{|l|}{ Dealing with theoretical constructs } \\
\hline EMPHASIZE a theoretical construct & $\begin{array}{l}\text { One theoretical construct is repeatedly emphasized and connected to different classroom } \\
\text { situational demands; this is also done throughout different modules. }\end{array}$ \\
\hline OMIT a theoretical construct & Some theoretical constructs are omitted or only treated very briefly. \\
\hline INTRODUCE a new construct situationally & $\begin{array}{l}\text { Some theoretical constructs are introduced at an appropriate moment while discussing rich } \\
\text { classroom demands }\end{array}$ \\
\hline
\end{tabular}


As these considerations suggest, some facilitators categorized the theoretical constructs as being basically research-based academic knowledge-for-practice that has to be thoroughly examined to determine whether it is digestible for novice teachers.

\section{Knowledge-in-practice foregrounded for the novice teachers} All facilitators emphasized that a major task for the novice teachers' first 2 years of teaching is to develop knowledge-inpractice, i.e., practical know-how for mathematics education in general and for the new PD content (language-responsive mathematics teaching). For this purpose, they emphasized that novice teachers require a general language awareness and concrete approaches for classrooms. Some facilitators chose discursively activating activity structures, others chose formats for supporting language (e.g., by sentence starters or word banks), and others emphasized the micro-scaffolding moves for facilitating classroom talk. With respect to knowledge-in-practice, concrete examples are welcome that can directly be used as tools in the classrooms or easily be transferred and then used (such as activity structures). Sometimes, examples are DETACHED (see Table 2) from the theoretical contexts they were originally intended to exemplify:

Drawing on this exact example, we simply talked concretely about different forms of help. (Mr. Soc, Interview Turn 104)

According to the original intention of the design team, the example Mr. Soc talks about was planned to introduce the important constructs of discourse practices and the idea that vocabulary support must always match with the demanded discourse practices. However, Mr. Soc decided to delay these distinctions and relations to another situation in the PD session and flattened the example to a pedagogical question of when to provide help in general. So the transformation here is from a central theoretical perspective (vocabulary should always be considered in its function for discourse practices) to a pedagogical technique (help must be minimal wherever possible). Whereas this adaptation action of DETACHING sometimes risks omitting a theoretical construct completely, Mr. Soc used another activity to introduce the relationships of mathematical goals, discourse practices, and vocabulary.

Another instance of foregrounding knowledge-in-practice is when examples are SELECTED only due to their fitting the grade level or mathematical topic. This again might DE$\mathrm{TACH}$ them from their theoretical context:

And the examples I select from topics, they are just involved with in their teaching, not like following a certain concept with the same examples over and over again. (Ms. Sour, Interview Turn 108)
I do think it is important, that they see as many examples as possible so that they can climb along them. (Ms. Sour, Interview Turn 100)

But for the novice teachers it would be good to have stuff that fits with their actual teaching. Because that's what they are thinking about. (Ms. Sour, Interview Turn 120)

Although none of these facilitators used the words knowledge-in-practice and knowledge-for-practice, they contrasted the forms of knowledge in own words and took this categorical distinction as a base for the selection choices and for thematic actions of detaching activities from theoretical backgrounds.

\section{Select and transform knowledge-for-practice into knowledge-of-practice and knowledge-in-practice}

Of course, all facilitators were aware that some theoretical constructs and design principles are crucial for guiding the classroom practices, and the weekly courses are the place to introduce these constructs as knowledgefor-practice and to let them emerge by the teachers' reflections as knowledge-of-practice, for example, the theoretical construct of the epistemic function of language that Ms. Rice and Ms. Sour EMPHASIZED repeatedly. Ms. Sour articulates:

Well, I do not see how I can avoid this [introducing some constructs]. Because, you have to move to the meta-level in the seminar, and there I will indeed probably need the vocabulary. (Ms. Sour, Interview Turn 63)

... and that you actually notice that communication is not just talking, but essentially also has an epistemic function. This is what I wanted to work out by that. (Ms. Sour, Interview Turn 8)

However, all facilitators saw the risk of an overload of inactive constructs, especially in the basic module:

You could spend a three-hour seminar just with theory. But this is not bearable nor does it make sense at that point. Because concrete practice orientation is just as important. Simply first to actually understand the topic and to make it graspable for oneself. Well, and second, by pure psychology, because one is not able to absorb all that. (Mr. Soc, Interview Turn 33)

They dealt with this risk by OMITTING constructs, RE-SORTING the sequencing, or SPLITTING the sessions. As knowledge-for-practice always risks that knowledge will remain inert (Renkl et al., 1996) when 
not connected to the concrete classroom practices, the facilitators adopted different strategies to transform the knowledge-for-practice into knowledge-inpractice or knowledge-of-practice:

During the group discussions, many facilitators valued the activity on simplifying texts, not only due to the practical relevance, but also due to the potential to activate knowledge-of-practice. Here, the theoretical constructs that were introduced as knowledge-for-practice were transformed into knowledge-in-practice relevant for a practical classroom task. One facilitator reported on an emerging knowledge-of-practice:

It allows working through the different language levels and language features for a very practical purpose.

(Ms. Fev, Group Discussion 4)

My novice teachers realized that difficulties on the word level and the sentence level can be simplified, but the discourse level must retain the demands, hence they approached these constructs by reflection. (Ms. Fev, Group Discussion 3)

Transferring these experiences, some facilitators consequently tried to start from concrete classroom professional demands (such as planning a teaching unit with mathematical and language-related goals) and SITUATIONALLY INTRODUCE those constructs that are required for coping with these demands:

We hadn't treated that, but I situationally included it when discussing the classroom experiment, and the teacher took the vocabulary immediately as it fit her experiences. (Ms. Rice, Group Discussion 3)

In this way, the knowledge-for-practice is considered to be transformed into knowledge-of-practice, since the research-based knowledge now serves to structure the teachers' own experiences and actions in a reflective way. In a similar way, this happened when the facilitators LET the novice teachers ADAPT or EXTEND examples.

And then we tried to transfer that to our own examples, where the novice teachers have found examples from their actual teaching. (Ms. Rice, Interview Turn 35)

One facilitator, Mr. Soc, worked intensively on his newly acquired knowledge-for-practice by CREATING a completely new teaching unit by himself and integrating all theoretical constructs into this work. In this way, he has turned his knowledge-for-practice into his personal knowledge-of-practice as both a teacher and a facilitator. When bringing this experience to the group discussions, he reports:

I had to do that for me to think through everything we discussed. Now I understand better what belongs to what. (Mr. Soc, Group Discussion 3)

He reduced the amount of theoretical constructs by integrating them into a single example rather than many. For his novice teachers, he turned the constructs into concrete tasks of planning and suggested them as knowledge-in-practice.

Two facilitators emphasized the need to ADAPT or EXTEND examples into ones that the novice teachers can use immediately in their classrooms. Whereas one facilitator emphasized the need for these examples to support concrete actions (knowledge-in-practice), the other one emphasized the need for teachers to experiment with and reflect on their own experiences (knowledge-of-practice):

Because I think the novice-teachers would learn the most by applying things that they hear in the seminar and experience them first-hand. And so, not just as a supply unit, as a theoretical construct ... (Ms. Sour, Interview Turn 118)

It [the design principle for the language-responsive teaching unit on percentages presented in the material] worked out so perfectly, unbelievable in fact, and in other teaching units that were planned just as well, it did not work out at all. There, one could not apply that [the design principle] at all and then they [the novice teachers] said, what am I supposed to write here, this, like, does not work at all. I found that really straining and then I just said, we will see, we will simply try it out then. (Ms. Rice, Interview Turn 6)

The last utterance in particular hints at a specific strategy that Ms. Rice uses: She engages her novice teachers and herself in joint explorations and adopts an inquiry stance. In this way, the ADAPTATION of examples may transform knowledge-for-practice and a delivered example with knowledge-in-practice into reflective knowledge-of-practice that is also enriched by knowledge about limitations.

In sum, it is exactly this very sophisticated way of reason about transforming different forms of knowledge that is the main characteristic of the expert facilitators' specific pedagogical design capacity: The personal categories they activate concern their participants' acquisition of different forms of knowledge. 


\section{Discussion}

In this section, we (a) summarize the findings, (b) discuss them with respect to existing findings for teachers, (c) highlight limitations of the study and future research needs, and (d) suggest consequences for designing PD curriculum materials as OER.

\section{(a) Summary of major findings: disentangling expert facilitators' adaptation practices and underlying categories}

In this article, we adopted the research approach of describing and explaining curriculum adaptation practices and lifting it from teachers' adaptation practices to facilitators' practices: The facilitators investigated in this study were shown to have high "pedagogical design capacities" in the sense of Brown (2009). Summing up the major findings, the study reveals:

- Facilitators' materialized adaptation actions not only refer to complete modules, but mainly to thematic blocks and single activities or slides, so these thematic units must be explicitly made visible in the material (RQ1).

- Facilitators' thematic adaptation actions for dealing with examples and theoretical constructs seemed to play a central role for the quality of the adaptation. The facilitators intend to shift between different kinds of knowledge, for example, from knowledge-for-practice to knowledge-of-practice (RQ2).

\section{(b) Discussion of major findings}

With respect to research question RQ 1on materialized adaptation actions, the whole spectrum of teachers' materialized adaptation actions for curriculum materials from following to improvising and everything in between (Brown, 2009), with omitting, modifying, and creating (Sherin \& Drake, 2009), could be replicated and even be further refined. The newly developed FOMSC scheme allows capturing materialized adaptation actions for different grain sizes of PD materials (course, module, themes/ atomic activities, or slides). We identified all five materialized adaptation actions on nearly all material grain sizes, even with a small sample size of 11 facilitators, but most frequently the facilitators OMIT thematic blocks or slides or CREATE and SORT thematic blocks. These results seem to largely resonate with research results on teachers' adaptation practices (Davis et al., 2011; Sherin \& Drake, 2009) but also shed light on the necessity to distinguish the grain sizes of materials more systematically (Fig. 6).

The categories underlying the materialized adaptation actions were analyzed to explain the facilitators' decisions. The facilitators' high degree of pedagogical design capacity is expressed by the richness of references to their personal resources (Brown, 2009). This becomes particularly apparent in their identification of key affordances within the OER materials and their capacity to use their understanding of the PD content to meet their novice teachers' needs as learners while considering circumstances such as time shortage and frames. In contrast to the preliminary study on other groups of facilitators (Zwetzschler et al., 2016), the intense

\section{Descriptive Findings: \\ How do facilitators adapt?}

Explanative Findings: Based on which categories do facilitators adapt?

\section{Materialized Adaptation Actions \\ FOLLOW, OMIT, MODIFY, SORT, CREATE \\ on the grain sizes of course, module, thematic block, activities / slides}

Thematic Adaptation Actions

CREATE, FOLLOW, OMIT, ADJUST, DETACH classroom examples

EMPHASIZE, OMIT, SITUATLIVELY CONNECT theoretical constructs

Transformations between forms of knowledge

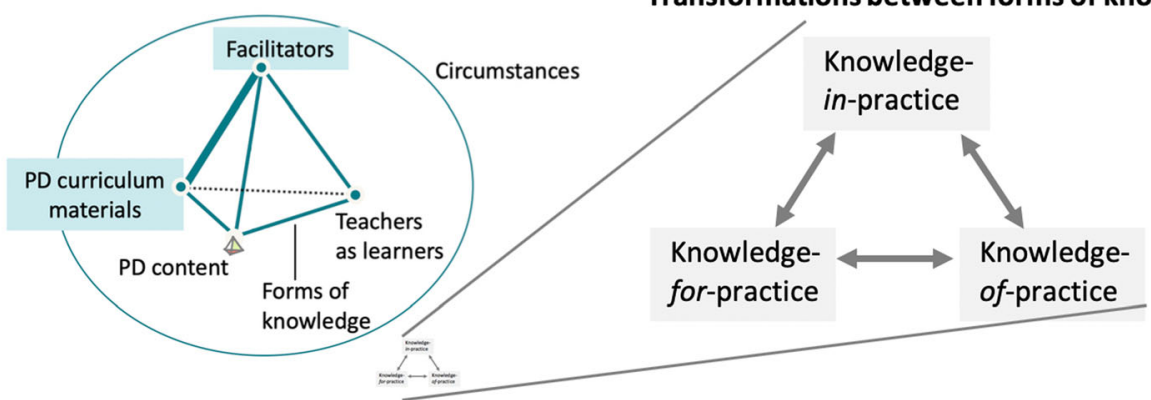

Fig. 6 Summary of frames for descriptive and explanative findings 
preparation by the group of expert facilitators in this particular study revealed a richness in different categories on the edge between PD content and teachers as learners that provides evidence for a richer understanding of participant orientation. In particular, the facilitators' considerations for taking into account the novice teachers' learning starting points, perceived learning needs, support for concrete teaching demands, and the danger of novice teachers' theoretical overload led to deep revisions of the PD curriculum material and to a further analysis of the thematic adaptation practices.

Hence, for the materialized adaptation actions and the underlying categories, our study confirms that there are many similarities between the facilitators' and teachers' materialized adaptation practices. There are apparent parallels, particularly in terms of how much they consider their participants' needs while reasoning on their use of material, but the quality of adaptations seems to depend also on the grain sizes they act upon. The latter observation might also be relevant to investigate for teachers' adaptations.

With respect to research question $R Q 2$, thematic adaptation actions have a completely different structure, as they mainly tackle the content-related challenges of dealing with examples and theoretical elements. The descriptive results collected in Table 2 have the potential to unpack typical discourses of discussing the theory-practice relationship when facilitators mediate between the research-based knowledge and theoretical constructs and the teachers as learners with their practical needs (Jaworski \& Huang, 2014). The differences between the actions (in Table 2) "following examples with their theoretical embedding," "detaching the example from the theoretical embedding," and "adapting them to new mathematical topics" resonate with the adaptation actions for theoretical constructs: "emphasize constructs," "omit them," or "work with them situationally when required for systematizing a practical experience." Roughly speaking, facilitators and classroom teachers may share similarities in how they design to "train" or "teach" contents. But, regarding the endeavor to "train to transmit or train to teach," there is a substantial and systematic difference between facilitators' and classroom teachers' approaches to new materials that have not yet been covered in existing conceptualizations of teachers' curriculum use (Brown, 2009; Davis et al., 2011, etc.). Here, the ambiguity of different forms of knowledge and their relationship to practice becomes apparent and needs to be unpacked in more detail (Prediger et al., 2019).

In order to explain the different priorities in the thematic adaptation actions, we were able to infer categories referring to implicit or explicit transformations between forms of knowledge (Cochran-Smith \& Lytle, 1999): A researchbased PD program always risks prioritizing knowledge-forpractice (theoretical constructs for language-responsive mathematics teaching), and the observed facilitators valued this form of knowledge for their personal background. At the same time, they assumed responsibility mainly for increasing novice teachers' knowledge-in-practice and knowledge-of-practice. In the preliminary study (Zwetzschler et al., 2016), the less experienced facilitators flattened the content into knowledge-in-practice by detaching examples from their theoretical context and by disconnecting the knowledge-for-practice from the rest. In contrast, the expert facilitators in the current study transformed knowledge-for-practice into knowledge-of-practice for novice teachers' planning and reflecting on their personal classroom experiences. These kinds of practices for shifting between forms of knowledge must be focused on much more in further research, including also those on the level of the teacher.

\section{(c) Limitations of the study and future research}

Although our findings originate from extensive data analysis, there are some crucial limitations to the explanatory value of our study. With only 11 expert facilitators and only six in the focus interviews, the sample size is still too small for statistical generalizations of the findings. As self-reports on adaptation practices can only cover a small part of the adaptation process, namely, those activities that are consciously undertaken and remembered, we can only account for these adaptation strategies and underlying perspectives. Even if the adapted materials were part of the data corpus, there are still many unconscious and spontaneous adaptation actions happening in the PD session itself (similar to teachers' adaptations, e.g., Sherin \& Drake, 2009). A future study on adaptation strategies should fill that gap and capture the facilitators' PD facilitation practices by observing the PD sessions and studying the curriculum that is actually enacted in the classroom.

Additionally, the specificity of the sample to which these results are tied must be taken into account. The facilitators' particularly intense contact with the design team and with their participants seemed to empower the well-reflected adaptations in the investigated sample. In future research, more distant facilitators without prior preparation by the design team should also be investigated, as this group is also addressed by OER in general. In these cases, the facilitators' subtle processes of transforming knowledge forms also require further investigation as they put the role of the facilitator as a mediator into the center (Jaworski \& Huang, 2014).

\section{(d) Consequences for the design of PD curriculum material as OER}

The starting point of the article was the need for an empirical base for the material strategy of scaling up, 
especially for OER in PD programs that are not highly specified and that are outside implementation studies.

- With respect to the materialized adaptation actions, the consequences are crucial for further pushing the simultaneous work on the quality and flexibility of OER: In particular, OER should support and encourage adaptations of a course by making explicit proposals for selecting modules or individual thematic blocks (M-F, M-O, M-S, T-F, T-O, T-S) and the adaptation of slides and activities ( $\mathrm{S}-\mathrm{M}, \mathrm{A}-$ $\mathrm{M})$. Omitting individual slides or activities (S-O, A$\mathrm{O})$ that are not marked optional hints at the material that needs improvement for possible re-use.

- With respect to the thematic adaptation actions, one major consequence the design team drew from these empirical findings is that the material was restructured in order to elaborate more explicitly how the theoretical constructs (knowledge-for-practice) can also have a second function as knowledge-ofpractice. The redesign of the material drew upon the facilitators' reported adaptations and provided learning opportunities for knowledge-of-practice or even turned it into very concrete guidance for action as knowledge-in-practice without detaching it from its theoretical context. For example, the theoretical constructs provided for specifying students' academic language demands are now actively invented in an activity where teachers support students by the development of sentence frames rather than by a general, abstract discussion of language demands (Prediger, 2019). In this way, the expert facilitators' strategies were partly picked up in the final form of the material. There is a further plan to offer several pathways to the same theoretical construct, which allows its use for various classroom demands and the selection of material without loss of theoretical background. Conversely, activities have to be closely connected to their theoretical background and the classroom situations for which it is relevant, so that less experienced facilitators can also adapt it without neglecting the knowledge-of-practice.

Although valuable consequences could be drawn for the design of OER, further research is needed for this new movement in order to assure quality.

\section{Conclusion}

For classroom curriculum materials, teachers' typical adaptation practices and the possible backgrounds in their underlying perspectives have been well documented. This article reports on a study that has lifted this research perspective from the level of teachers' adaptations with classroom materials to PD facilitators' practices with PD curriculum materials. The study has investigated the adaptation practices of 11 expert facilitators and their underlying individual perspectives in group discussion and interviews. The qualitative analysis showed that all materialized adaptation actions (follow, omit, modify, sort, and create) were conducted on different grain sizes of PD material chunks and with various underlying perspectives for which the participant orientation is crucial. These results seem to largely resonate with research results on teachers' adaptation practices, but shed light on the necessity to distinguish the grain sizes more systematically.

Additionally, thematic adaptation actions that capture facilitators' ways of dealing with examples and theoretical constructs were identified. These findings go beyond the current state of research and reveal that dealing with examples often involves shifts in the forms of knowledge, for example, when facilitators situate a theoretical construct in concrete classroom practices.

These findings imply practical consequences for the design of PD curriculum material, especially when distributed as open educational resources: To ensure that adaptation practices retain or improve quality, the structure of PD curriculum material must make explicit the minimal adequate grain size to be modified (better the thematic block than the single slide) and the need for shifts in the forms of addressed knowledge from abstract knowledge-for-practice to situated knowledge-of-practice.

\section{Abbreviations \\ DZLM: Deutsches Zentrum für Lehrerbildung Mathematik; FOMSC scheme: Code system for materialized adaptation actions FOLLOW (F), OMIT (O), MODIFY (M), SORT (S) and CREATE (C) on four grain sizes: Course (C), Module (M), Thematic Bloc (T), Slide (S) or activity (A); OER: Open educational} resources; PD: Professional development

\section{Acknowledgements}

We thank the participating facilitators for their collaboration in the group discussions and interviews and Jim Hostetter for his language editing.

\section{Authors' contributions}

All four authors work within the DZLM, the German Center for Mathematics teacher education. NL was working on the project for 6 months as a postdoc, SP and UK are full professors and the PIs of the project, and PM is a PhD student working in the project. The project was designed and the project proposal was written by SP and UK. The data collection and initial data analysis were conducted by NL and PM and the completion of the data analysis and the writing by all four. The order of the authors reflects their contributions to the article. All authors read and approved the final manuscript.

\section{Funding}

The presented study was conducted in the DZLM (German Center of Mathematics Teacher Education, financially supported by the German Telekom Foundation) within the projects OER-Mat^3 and MuM-Innovation, which are funded by the German Ministry of Education and Research (Grant no. 01P016023A/B to S. Prediger and U. Kortenkamp and Grant no. 03VP02270 to S. Prediger). The data was gathered within MuM-Innovation and analyzed within OER. We acknowledge the financial support by Deutsche Forschungsgemeinschaft and Technische Universität Dortmund/TU Dortmund University within the funding program Open Access Publishing. 


\section{Availability of data and materials}

The transcripts used and analyzed during the current study are available (in their original language German) from the corresponding author on reasonable request.

\section{Competing interests}

The authors declare that they have no competing interests.

Received: 16 October 2018 Accepted: 10 June 2019

Published online: 01 July 2019

\section{References}

Borko, H., Jacobs, J., Koellner, K., \& Swackhamer, L. E. (2015). Mathematics professional development: Improving teaching using the problem-solving cycle and leadership preparation models. Reston: NCTM.

Borko, H., Koellner, K., \& Jacobs, J. (2014). Examining novice teacher leaders' facilitation of mathematics professional development. Journal of Mathematical Behavior, 33, 149-167.

Bromme, R. (1992). Der Lehrer als Experte. Bern: Huber.

Bromme, R. (2001). Teacher expertise. In N. J. Smelser \& P. B. Baltes (Eds.), International encyclopedia of the social and behavioral sciences (pp. 1545915465). Amsterdam: Elsevier.

Brown, M. W. (2009). The teacher-tool relationship. Theorizing the design and use of curriculum materials. In J. T. Remillard, B. A. Herbel-Eisenmann, \& G. M. Lloyd (Eds.), Mathematics teachers at work: Connecting curriculum materials and classroom instruction (pp. 17-36). New York: Routledge.

Butcher, N. (2015). A basic guide to open educational resources (OER). Paris: Commonwealth of Learning; United Nations Educational, Scientific and Cultural Organization (UNESCO) http://hdl.handle.net/11599/36 [Last accessed 6 Mar 2019].

Coburn, C. E. (2003). Rethinking scale: Moving beyond numbers to deep and lasting change. Educational Researcher, 32(6), 3-12.

Cochran-Smith, M., \& Lytle, S. L. (1999). Relationships of knowledge and practice: Teacher learning in communities. Review of Research in Education, 24(1), 249-305.

Davis, E. A., Beyer, C., Forbes, C. T., \& Stevens, S. (2011). Understanding pedagogical design capacity through teachers' narratives. Teaching and Teacher Education, 27(4), 797-810.

Dusenbury, L., Brannigan, R., Falco, M., \& Hansen, W. B. (2003). A review of research on fidelity of implementation. Health Education Research, 18(2), 237256. https://doi.org/10.1093/her/18.2.237.

Eisen, V., Kietzmann, U., Prediger, S., Şahin-Gür, D., Wilhelm, N., \& Benholz, C. (2017). Sprachsensibles Unterrichten fördern im Fach Mahematik. In S. Oleschko (Ed.), Sprachsensibles Unterrichten fördern: Angebote für den Vorbereitungsdienst (pp. 188-237). Arnsberg: LAKI.

Even, R., \& Krainer, K. (2014). Education of mathematics teacher educators. In S. Lerman (Ed.), Encyclopedia of mathematics education (pp. 202-204). Heidelberg: Springer.

Jacobs, J., Seago, N., \& Koellner, K. (2017). Preparing facilitators to use and adapt mathematics professional development materials productively. International Journal of STEM Education, 4(1), 3no page numbers. https://doi.org/10.1186/ s40594-017-0089-9.

Jaworski, B., \& Huang, R. (2014). Teachers and didacticians: Key stakeholders in the processes of developing mathematics teaching. ZDM Mathematics Education, 46(2), 173-188.

Kuzle, A., \& Biehler, R. (2015). Examining mathematics mentor teachers' practices in professional development courses on teaching data analysis. ZDM Mathematics Education, 47(1), 39-51.

LeMahieu, P. (2011). What we need in education is more integrity (and less fidelity) of implementation. Carnegie Foundation Blog Retrieved from https://www. carnegiefoundation.org/blog/what-we-need-in-education-is-more-integrityand-less-fidelity-of-implementation/ [Last accessed 6 Mar 2019].

Lesseig, K., Elliott, R., Kazemi, E., Kelley-Petersen, M., Campbell, M., Mumme, J., \& Carroll, C. (2017). Leader noticing of facilitation in videocases of mathematics professional development. Journal of Mathematics Teacher Education, 20(6), 591-619.

Maaß, K., \& Artique, M. (2013). Implementation of inquiry-based learning in dayto-day teaching: A synthesis. ZDM Mathematics Education, 45(6), 779-795.

Maaß, K., \& Doorman, M. (2013). A model for a widespread implementation of inquiry based learning. ZDM - Mathematics Education, 45(6), 887-899.
Martin, J. (1983). Managing the data-base environment. Englewood Cliffs: Prentice-Hall.

Mayring, P. (2015). Qualitative content analysis: Theoretical background and procedures. In A. Bikner-Ahsbahs, C. Knipping, \& N. Presmeg (Eds.), Approaches to qualitative research in mathematics education (pp. 365-380). Dordrecht: Springer.

Prediger, S. (2019online first)). Promoting teachers' pathways towards expertise for language-responsive mathematics teaching - a design research study. Mathematics Education Research Journal. https://doi.org/ 10.1007/s13394-019-00258-1.

Prediger, S., Roesken-Winter, B., \& Leuders, T. (2019, online first). Which research can support PD facilitators? Research strategies in the Three-Tetrahedron Model for content-related PD research. Journal of Mathematics Teachers Education. doi: https://doi.org/10.1007/s10857-019-09434-3.

Remillard, J. T. (2005). Examining key concepts in research on teachers' use of mathematics curricula. Review of Educational Research, 75(2), 211-246.

Remillard, J. T., \& Bryans, M. B. (2004). Teachers' orientations toward mathematics curriculum materials: Implications for teacher learning. Journal for Research in Mathematics Education, 35(5), 352-388.

Renkl, A., Mandl, H., \& Gruber, H. (1996). Inert knowledge: Analyses and remedies. Educational Psychologist, 31(2), 115-121.

Rezat, S., \& Sträßer, R. (2012). From the didactical triangle to the socio-didactical tetrahedron: Artifacts as fundamental constituents of the didactical situation. ZDM - Mathematics Education, 44(5), 641-651.

Roesken-Winter, B., Hoyles, C., \& Bloemeke, S. (2015). Evidence-based CPD: Scaling up sustainable interventions. ZDM Mathematics Education, 47(1), 1-12. https://doi.org/10.1007/s11858-015-0682-7.

Schifter, D., \& Lester, J. B. (2002). Active facilitation: What do facilitators need to know and how might they learn it? The Journal of Mathematics and Science: Collaborative Explorations, 8, 97-118.

Sherin, M. G., \& Drake, C. (2009). Curriculum strategy framework: Investigating patterns in teachers' use of a reform-based elementary mathematics curriculum. Journal of Curriculum Studies, 41(4), 467-500.

Stein, M. K., Remillard, J., \& Smith, M. (2007). How curriculum influences student learning. In F. K. Lester (Ed.), Second handbook of research on mathematics teaching and learning (pp. 319-369). Charlotte: Information Age.

Stein, M. K., Smith, M. S., \& Silver, E. A. (1999). The development of professional developers: Learning to assist teachers in new settings in new ways. Harvard Educational Review, 69(3), 237-269.

Tekkumru-Kisa, M., \& Stein, M. K. (2017). Designing, facilitating, and scalingup video-based professional development: Supporting complex forms of teaching in science and mathematics. International Journal of STEM Education, 4(1), 27(no page numbers). https://doi.org/10.1186/s40594017-0087-y.

Trouche, L., Gueudet, G., \& Pepin, B. (2018). Open educational resources: A chance for opening mathematics teachers' resource systems? In L. Fan, L. Trouche, C. Qi, S. Rezat, \& J. Visnovska (Eds.), Research on mathematics textbooks and teachers' resources - advances and issues (pp. 3-27ICME 13 Monograph). New York: Springer.

Wiley, D. (2014). Defining the 'open' in open content. Open Content Retrieved from https:/www.opencontent.org/definition/ [Last accessed 6 Mar 2019].

Zwetzschler, L., Rösike, K., Prediger, S., \& Barzel, B. (2016). Professional development leaders' priorities of content and their views on participant-orientation. Hamburg: Paper presented in TSG 50 at ICME 13 Retrieved from http://www. mathematik.uni-dortmund.de/ prediger/veroeff/16-ICME-FacilitatorsZwetzschler-etal.pdf [Last accessed 6 Mar 2019].

\section{Publisher's Note}

Springer Nature remains neutral with regard to jurisdictional claims in published maps and institutional affiliations. 